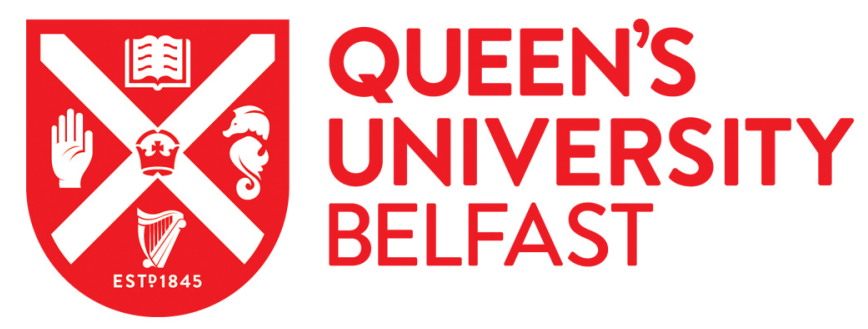

\title{
Measuring and modelling air mass flow rate in the injection stretch blow moulding process
}

Salomeia, Y., Menary, G. H., Armstrong, C. G., Nixon, J., \& Yan, S. (2016). Measuring and modelling air mass flow rate in the injection stretch blow moulding process. International Journal of Material Forming, 9(4), 531-545. https://doi.org/10.1007/s12289-015-1240-0

Published in:

International Journal of Material Forming

Document Version:

Peer reviewed version

Queen's University Belfast - Research Portal:

Link to publication record in Queen's University Belfast Research Portal

Publisher rights

Copyright 2015 Springer

The final publication is available at Springer via http://dx.doi.org/10.1007/s12289-015-1240-0"

\section{General rights}

Copyright for the publications made accessible via the Queen's University Belfast Research Portal is retained by the author(s) and / or other copyright owners and it is a condition of accessing these publications that users recognise and abide by the legal requirements associated with these rights.

Take down policy

The Research Portal is Queen's institutional repository that provides access to Queen's research output. Every effort has been made to ensure that content in the Research Portal does not infringe any person's rights, or applicable UK laws. If you discover content in the Research Portal that you believe breaches copyright or violates any law, please contact openaccess@qub.ac.uk. 
Measuring and Modelling Air Mass Flow Rate in the Injection Stretch Blow Moulding Process Y. Salomeia ${ }^{1}$, G. H. Menary ${ }^{2}$, C. G. Armstrong 2 , J. Nixon ${ }^{2}$, S. Yan ${ }^{2}$

${ }^{1}$ Blow Moulding Technologies, 125 Stranmillis Road, BT9 5AH, Belfast, Northern Ireland, U.K. yannis@bmt-ni.com

${ }^{2}$ School of Mechanical and Aerospace Engineering, Queen's University of Belfast, BT9 5AH, Belfast, Northern Ireland, U.K.

Contact Information for Corresponding Author

James Nixon

Queen's University Belfast

School of Mechanical \& Aerospace Engineering

Ashby Building

Stranmillis Road

Belfast BT9 5AH

Northern Ireland

Tel: +44 (0)289097 5523

Email: jnixon05@qub.ac.uk 


\begin{abstract}
The injection stretch blow moulding process involves the inflation and stretching of a hot preform into a mould to form bottles. A critical process variable and an essential input for process simulations is the rate of pressure increase within the preform during forming, which is regulated by an air flow restrictor valve. The paper describes a set of experiments for measuring the air flow rate within an industrial ISBM machine and the subsequent modelling of it with the FEA package AbaqusABAQUS. Two rigid containers were inserted into a Sidel SBO1 blow moulding machine and subjected to different supply pressures and air flow restrictor settings. The pressure and air temperature were recorded for each experiment enabling the mass flow rate of air to be determined along with an important machine characteristic known as the 'dead volume'. The experimental setup was simulated within the commercial FEA package AbaqusABAQUS/Explicit using a combination of structural, fluid and fluid link elements that idealize the air flowing through an orifice behaving as an ideal gas under isothermal conditions. Results between experiment and simulation are compared and show a good correlation.
\end{abstract}

Keywords: Stretch blow moulding, simulation 


\subsection{Introduction}

Injection Stretch Blow Moulding (ISBM) is the widely used process to manufacture Polyethylene terephthalate (PET) bottles for the beverage and consumer goods industry. With the ever growing cost of raw materials and rapidly increasing competition, PET bottle manufacturers have been trying to push their limits to reduce the weight of the bottle without compromising the in service performance and aesthetics of the bottle.

The existing industrial state of the art in injection stretch blow moulding involves trial and error approaches on a single cavity ISBM machine to determine appropriate machine settings for industrial production. Depending on the bottle and performpreform design this can take several days to complete. Most of the research over the last 20 years has focused on developing numerical simulations to overcome this empirical approach and replace it with a more scientific method whereby one can predict the process conditions and their effect on material thickness distribution and material properties in advance.

Chevalier et al. has focused on modelling how PET behaves during processing and how processing influences microstructure and macroscopic material properties $[1,2]$. An aspect of their work has focused on developing a blow moulding simulation based on the Constrained Natural Elements Method (C-NEM) which has the advantage of not requiring any re-meshing even when the elements are subjected to high strains [3]. The simulation is still at an early stage of development and no correlation between simulation and experiment is available. Billon et al. [4] has focused on understanding how PET behaves during stretch blow moulding. The microstructure of formed bottles and 'free blown' bottles have been analysed showing how the crystallinity and orientation develops during stretch blow moulding and a numerical model of PET has been developed to capture these features based on an Edwards Vilgis hyperelastic model. Hopmann et al. [5] have 
developed an integrated blow moulding simulation approach where 3 simulations are integrated together to model the complete history of the performpreform. The $1^{\text {st }}$ stage simulates the preform during the heating phase which predicts a temperature profile of the preform. This temperature profile is subsequently used in a blow moulding simulation which predicts wall thickness and mechanical properties. These predictions are then fed into in-service performance simulations for top load and shelf life. Results for all stages correlate well with experiment although the results are only presented for one test case and no information is provided on the validity of the temperature predictions. The work by Erichiqu et al [6] identified the need for modelling inflation processes by using a fluid flow approach, when considering inflation of a thin membrane; however their focus was on the mathematical implementation of this within FEA code rather than measurement and validation.

Bordival et al. [7] developed an IR heating and ISBM simulation. They coupled the ISBM simulation to an optimization algorithm with the aim of predicting optimum preform temperature profile that gave the most uniform wall thickness. The IBSM simulation used a fluid structure type approach within the commercial FEA package ABAQUS to calculate the air pressure. Corresponding experiments were performed on a simple prototype rig which could heat the preform, and then blow it into a simple mould without a stretch-rod. The rig was able to measure the pressure inside the preform whilst the mass flow rate was measured using a hot wire sensor. The sensor indicated that the mass flow was non-linear, rising exponentially to a peak before decaying gradually to zero. It is not mentioned about the response time of the sensor and its possible effect on the measurements and there are no details of the pneumatic circuit on the test rig used. It is important to note however that the timescale of inflation on this simple rig $(4 \mathrm{sec})$ is not comparable with that observed on an industrial ISBM machine where the bottle is typically 
inflated in under $300 \mathrm{~ms}$ [8]. The difference in timescales suggests that the sensor may be unsuitable for use on an industrial blow moulding machine as it is unlikely to be able to cope with the transient flows experienced. The ISBM simulation also incorporates heat transfer between the mould and the preform and experimental data is presented for the heat transfer coefficient. The simulation had reasonable predictions for pressure evolution although the aggressive pressure drop due to the large volume increase rate during bubble formation was predicted to be too fast i.e. the bubble initiated too quickly in the simulation. The thickness distribution of the formed bottle was predicted with a $15 \%$ error. An example of the potential power of ISBM simulation is shown by coupling it to an optimization algorithm with the objective to produce a bottle with a uniform wall thickness by modifying the preform temperature. Schmidt et al. [9] incorporated instrumentation on a stretch blow moulding machine and noted that the pressure in the preform was substantially different to that of the line pressure. They propose a coupled model for the thermodynamics of the air and for the thermo mechanical inflation of the preform. They highlight the importance of measuring the flow rate to accurately capture the pressure in the preform and suggest an experiment involving pressurizing of a rigid volume. This methodology is explored in this paper. Mir et al [10] also highlighted the fact that the pressure inside the preform is not constant and the need to impose a mass flow rate of air rather than a directly applied pressure to accurately model this. They use a thermodynamic energy balance approach to calculate the flow rate based on the energy supplied from the air compressor. This is a reasonable first approximation but it is important to note that there are no validation measurements and that the process is more complex than this idealization e.g. typically the machine operator, when optimizing their process, tweaks a flow control valve as the air enters the preform, thus altering the flow rate. Menary et al. [11] in collaboration with Billon conducted free-blow trials on an instrumented prototype rig. Simulations 
of the free-blow trials were developed and compared with the videos and the measured process variables of pressure, stretch rod force and local stretch ratio on the preform. Two approaches were taken for the simulation (i) the pressure was applied directly and measured (ii) a uniform mass flow rate was applied to the preform that was calculated based on the volume evolution of the preform and pressure inside it. The results highlighted that the mass flow rate approach was more realistic with excellent correlation between experiment and simulation. In order to develop reliable validated modelling, instrumentation of the process is vital to ensure accurate and reliable input of processing conditions into the simulation and for validating the outputs from the simulation. Recent work by the authors $[8,12]$ has involved building a wireless data acquisition system for measuring pressure inside the preform, stretch rod force, stretch rod displacement and air temperature inside the preform. This device is distinctive in that it is portable and can be mounted on industrial ISBM machines. In addition sensors have been incorporated inside a mould to measure the moment of contact when the preform touches the mould surface and a separate patented rig has been developed for measuring the inner and outer surface temperatures of the preform. These devices have enabled exact quantification of the process variables that are needed as inputs to the ISBM simulation. The challenge remains however to accurately quantify the flow rate of air in an ISBM machine and to accurately represent it within an ISBM simulation. The work in this paper will use this instrumentation system to measure the pressure and temperature within the preform and hence enable the mass flow rate to be calculated.

It is clear from the reviewing the literature that there is a need to measure and model the air flow within an ISBM machine in order to accurately represent the critical process variable of pressure within an ISBM process simulation. In this paper we perform practical experiments to measure the 
mass flow rate and setup a corresponding model of the thermodynamic process within the commercial finite element package ABAQUS.

\subsection{Experimental Setup}

All experiments were performed at Logoplaste Technologies (Cascais, Portugal). In this case the blow moulding machine used was a single mould automatic SBO1 stretch blow moulding machine from Sidel $\mathbb{C}$ Company. A simplified schematic diagram of the ISBM pneumatic system is shown in Fig. 1.

The ISBM machine has a large buffer tank that stores air at 3.5MPa gauge pressure. Subsequently two lines for the pre-blow and final blow stages run from this tank. For the pre-blow, the pressure is regulated down to a pressure in the range of 0.6 to $1.1 \mathrm{MPa}$ gauge pressure. The two lines are fed to a complex valve block that commutes between pre-blow, final-blow and exhaust. For simplicity in Fig. 1 only the shut off valve corresponding to the pre-blow stage is represented. In addition, upstream of the shut off valve a flow control valve is mounted to limit the maximum rate at which the air enters the cavity. The flow control valve used in this work has a scale of 12 units; however, beyond index 6 , in this system, it behaves as a fully opened valve. How an index on the valve corresponds to flow resistance in a given set of units is not known.

During the pre-blow stage the preform expands rapidly requiring a large mass of air. For this reason the pre-blow supply pipe between the pressure regulator and valve block is typically large in diameter and in this case equates to a volume around 6 times the volume of the final bottle. This arrangement behaves as a buffer and prevents a large drop in the pressure upstream of the valve block. 
The network of pipes typically found in industry connecting the compression stations and the ISBM machine buffer are vast and heat gained during compressing is lost to the environment. It is therefore reasonable to assume that the air entering the system is at room temperature.

Following the valve block the air flows through complex geometries such as pipes, elbows, sudden changes of section, ending with a flow straightener before it reaches the preform. Pressure drops are expected for such a pneumatic circuit, however, in this work they will not be considered.

The main attention is directed towards the flow control valve. It is typically used to finely adjust the process and it is the scope of this work to understand its effect. Such a restricting device causes significant pressure drop in the fluid. In the presented case, air can be considered both an ideal and compressible gas. For such a gas, the flow speed through a small cross section, such as the flow restrictor, reaches a limit when the absolute pressure ratio between the inlet and outlet is 0.528 . It is said that the flow is choked when the following condition is met:

$$
\frac{P_{\text {bottle }}}{P_{\text {line }}}<0.528
$$

Where $P_{\text {bottle }}$ is the pressure measured inside the bottle and $P_{\text {line }}$ is the supply pressure measured in the line.

The mass flow rate through the restriction is:

$$
\dot{m}=A \rho \mathcal{V}
$$

Where $A$ is the restrictor area; $\rho$ is the density of the fluid at the restriction which is assumed to be constant as we assume constant inlet pressure and $\mathcal{V}$ is the fluid velocity at the restriction.

For downstream pressures smaller than $0.528 P_{\text {line }}$ the mass flow is only influenced by the fluid conditions upstream of the nozzle. In this sense, if the pressure and temperature of air in the 
buffer tank remain constant the mass flow also remains constant as long as the choked condition is met, due to velocity limitations. Eventually the downstream pressure will rise above $0.528 \mathrm{P}_{\text {line }}$ as the volume of the bottle fills with air and the pressure increases. Beyond this condition the increase in pressure in the cavity reduces the mass flow rate through the nozzle.

In order to characterize the air mass flow, a series of experiments summarized in Table 1 were carried out involving charging two known fixed volumes. These volumes are essentially a rigid preform i.e. a preform at room temperature and a previously fully formed bottle constrained in a mould. Two levels of pressure and four settings of the flow restrictor over the range of interest were selected, resulting in 16 measurements.

\subsection{Rigid Volume Pressurisation}

Along with the pressure measurement the temperature of the air within the cavity was also measured via a fine wire thermocouple of $0.075 \mathrm{~mm}$ diameter embedded in the stretch rod. Fig. 2 and Fig. 3 shows the pressure and temperature vs. time for preform charging using a supply pressure of $0.7 \mathrm{MPa}$ respectively whilst Fig. 4 and Fig. 5 shows the pressure and temperature vs. time for bottle charging using a supply pressure of 0.7MPa respectively. Fig. 6 and Fig. 7 shows the pressure and temperature vs. time for preform charging using a supply pressure of $0.9 \mathrm{MPa}$ respectively whilst Fig. 8 and 9 shows the pressure and temperature vs. time for bottle charging respectively using a supply pressure of $0.9 \mathrm{MPa}$ respectively.

Once the shut off valve is opened the pressure increases until equilibrium with the pressure in the supply line is reached. Yet the pressure plateau reached is less than the nominal pressure. The 
inaccuracy comes from the analogue pressure gauge fitted on the machine, which is subject to human error when set. Nevertheless, this systematic error does not affect the measurements as great care was taken to be consistent in the adjustment of the pressure regulator.

The high index experiments reveal two characteristics of the pressure history. At the beginning the pressure has a gradual rise. This could be explained by inertia of the thermodynamic system or by a hysteresis of the pressure sensor. The second characteristic of the pressure measurement is the overshoot in pressure that appears with indexes greater than 3 on this particular flow restrictor valve. Such a simple experiment cannot reveal the precise reason for this phenomenon; however it is thought to be a due to shockwave over imposed on the real measurement. This is not likely to appear in the actual forming process as the preform will deform resulting in a reduction of pressure. It was observed that the air temperature inside the cold preform/bottle rose during the experiment. Moreover the temperature differs for different levels of line pressure and especially with flow index. This increase in temperature is normal and is due to the conversion of flow energy of the stream of air filling the chamber into internal energy and the compression of the air already found in the chamber. As expected, the minimum temperature rise of $\sim 5^{\circ} \mathrm{C}$ occurred for the low flow valve setting during pressurization of the bottle at the $0.7 \mathrm{MPa}$ supply pressure whilst the maximum temperature rise occurred for the high flow valve setting pressurizing the preform with a $0.9 \mathrm{MPa}$ supply pressure.

In order to explain the difference for different charging rates, analysis of what would be the expected temperature rise is performed. Referring back to Fig. 1 the dotted line indicates the control volume of interest. This is an unsteady process since the conditions within the control volume are changing over time. However, this can be analysed as a uniform-flow process assuming 
that the state of the fluid remains constant at the inlet. The case of an adiabatic vessel is considered where the volume is equal to the value of the dead volume plus the volume of the rigid container. The calculation of the dead volume inferred here is explained in detail in the next section.

Noting that the microscopic energies of flowing and non-flowing fluids are represented by enthalpy $\mathrm{h}$ and internal energy $\mathrm{u}$, respectively, the mass and energy balances for this uniform-flow system can be expressed:

Mass balance:

$$
m_{\text {in }}-m_{\text {out }}=\Delta m_{\text {system }}=m_{2}-m_{1}
$$

Where $m_{\text {in }}$ is the mass of air entering the system; $m_{\text {out }}$ is the mass of air leaving the system; $m_{2}$ is the mass of air in the preform/bottle at the end of the experiment and $m_{1}$ is initial mass of air in the preform/bottle.

Since $m_{\text {out }}=0$,

$$
m_{\text {in }}=m_{2}-m_{1}
$$

Energy balance:

$$
E_{\text {in }}-E_{\text {out }}=\Delta E_{\text {system }}
$$

Where $E_{\text {in }}$ is the Energy put in to the system; $E_{\text {out }}$ is the Energy leaving the system and $\Delta E_{\text {system }}$ is the change in Energy.

Since $E_{\text {out }}=0$,

$$
m_{\text {in }} h_{\text {in }}=m_{2} u_{2}-m_{1} u_{1}
$$

Which can be written as 


$$
m_{\text {in }} c_{p} T_{\text {in }}=m_{2} c_{v} T_{2}-m_{1} c_{v} T_{1}
$$

Where: $T_{\text {in }}$ is the temperature of air entering the system; $T_{2}$ is the temperature of air in the preform/bottle at the end of the experiment and $T_{1}$ is the initial temperature of air in the preform/bottle, $c_{p}$ is the specific heat capacity of air at constant pressure, $c_{v}$ is the specific heat capacity of air at constant volume.

Combining equation 4 and 7 :

$$
\left(m_{2}-m_{1}\right) c_{p} T_{i n}=m_{2} c_{v} T_{2}-m_{1} c_{v} T_{1}
$$

The initial and final masses are given by the equation of state:

$$
m_{1}=\frac{P_{1} V}{R T_{1}} \quad m_{2}=\frac{P_{2} V}{R T_{2}}
$$

Where: $P_{1}$ is the intial pressure in the preform; $P_{2}$ is the final pressure in the preform, $\mathrm{V}$ is the volume of the preform/bottle plus the dead volume and $\mathrm{R}$ is the gas constant,

Substituting the gas constant of air $\mathrm{R}=287 \mathrm{~Pa} \mathrm{~m}^{3} / \mathrm{kg} \mathrm{K}$ and the specific heats of air at the system

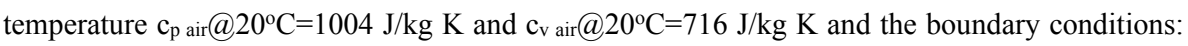
line pressure of $0.7 \mathrm{MPa}$, inlet air at $20^{\circ} \mathrm{C}$, and volume $\mathrm{V}=670 \cdot 10^{-6} \mathrm{~m}^{3}$ yields the temperature:

$\mathrm{T}_{2} \approx 118^{\circ} \mathrm{C}$ for $0.7 \mathrm{MPa}$ line pressure and $\approx 122^{\circ} \mathrm{C}$ for $0.9 \mathrm{MPa}$ line pressure.

These values indicate that if no heat is exchanged with the environment a significant increase in temperature is expected. The variation in temperature with the rate of charging is justified by the variation in time necessary to fill the volume which allows more time for heat exchange with the metallic components of the system. 
Due to difficulties encountered during mounting of the fine wire thermocouple only a $0.075 \mathrm{~mm}$ thermocouple wire could be installed. Some underestimation of the real temperature was expected, however, the maximum value recorded is around $53^{\circ} \mathrm{C}$, which is well below the calculated value. In addition it should be noted that the plotted temperature values are interpolated values and in reality the temperature acquisition rate was only $7 \mathrm{~Hz}$ due to hardware restrictions. In these conditions there is likelihood for aliasing to occur as the temperature oscillation happens quicker than the sampling rate resulting in measurements that may be potentially higher in magnitude being missed. Using a lumped capacitance method and treating the bead of the thermocouple as a sphere, equation 9 can be used to estimate the time constant $\tau$ of the thermocouple to detect a rise in air temperature from $20^{\circ} \mathrm{C}$ to $100{ }^{\circ} \mathrm{C}$ to be approximately 0.08 seconds. Considering the peak temperature rise is recorded within 0.06 seconds it seems likely that the response time of the thermocouple is affecting the results.

$$
\tau=\frac{\rho D c}{6 h}
$$

Where: $\rho$ is the metallic bead density $\left(8665 \mathrm{~kg} / \mathrm{m}^{3}\right), \mathrm{D}$ is the bead diameter $\left(0.1875 \cdot 10^{-3} \mathrm{~m}, \mathrm{c}\right.$ is specific heat respectively of the bead $(486 \mathrm{~J} / \mathrm{kg} \cdot \mathrm{K})$ and $\mathrm{h}$ is the convection coefficient which is estimated to be $1600 \mathrm{~W} / \mathrm{m}^{2} \cdot K$ from calculations based on a Nusselt number of 10 and a conductivity of air of $30 \cdot 10^{-3}(\mathrm{~W} / \mathrm{m} \cdot \mathrm{K})$

It can be concluded that the charging process in the given conditions is neither adiabatic nor isothermal but is more a "quasi-adiabatic" process with a polytropic index $\gamma$ in the range 1 to 1.4 depending on the charging rate. 


\subsection{Dead volume}

The summation of the individual volumes, described in the previous section, downstream of the flow control valve is part of the thermodynamic system considered in this work and it is referred to as 'dead volume' as it remains unchanged. An accurate value could not be found in the machine documentation and the detailed technical drawings are confidential. From visual inspection however, it was clear the volume is at least the same order of magnitude as the final volume of the bottle; hence some sort of calculation is needed to eliminate the inaccuracy in its value that could introduce significant errors in subsequent calculations for the mass flow rate.

The calculation is based on the experiment that involves charging of two containers of different known volumes in the case closest to an isothermal process i.e. low supply pressure $(0.7 \mathrm{MPa}$ and high restriction (index $=1$ ).

An assumption is made that the time scale of the experiments are considered slow to enable any heat generated to be dissipated and therefore both processes are isothermal. We also assume that due to the small opening of the flow restrictor the mass flow at that control volume is considered choked as long as the condition $\mathrm{P}_{\text {bottle }}<0.528 \mathrm{P}_{\text {line }}$ is satisfied.

Based on the equation of state, and assuming isothermal conditions, we define the rate of mass of air at any point in time in the system to be:

$$
m=\frac{\dot{d} p}{d t} \cdot \frac{V}{R T}
$$

Writing the mass flow for both cases: 


$$
\dot{m}_{\text {preform }}=\frac{d P_{A}}{d t} \cdot \frac{V_{A}}{R T}=\frac{d P_{A}}{d t} \cdot \frac{\left(V_{D}+V_{p}\right)}{R T} \dot{m}_{\text {preform }}=\frac{d P_{A}}{d t} \cdot \frac{V_{A}}{R T}=\frac{d P_{A}}{d t} \cdot \frac{\left(V_{D}+V_{p}\right)}{R T}
$$

Where $\mathrm{V}_{\mathrm{A}}=$ Volume composed of the volume that remains unchanged over the experiments (dead volume, $\left.\mathrm{V}_{\mathrm{D}}\right)$ plus the volume of a pre-form $\left(\mathrm{V}_{\mathrm{p}}\right)$

$$
\dot{m}_{\text {bottle }}=\frac{d P_{B}}{d t} \cdot \frac{V_{B}}{R T}=\frac{d P_{B}}{d t} \cdot \frac{\left(V_{D}+V_{b}\right)}{R T} \dot{m}_{\text {bottle }}=\frac{d P_{B}}{d t} \cdot \frac{V_{B}}{R T}=\frac{d P_{B}}{d t} \cdot \frac{\left(V_{D}+V_{b}\right)}{R T}
$$

Where $\mathrm{V}_{\mathrm{B}}=$ Volume composed of dead volume plus the volume of a fully formed bottle $\left(\mathrm{V}_{\mathrm{b}}\right)$

The choked condition therefore implies:

$$
\dot{\boldsymbol{m}}_{\text {preform }}=\dot{\boldsymbol{m}}_{\text {bottle }}
$$

Rearranging equations 10,11 , and 12 :

$$
V_{D}=\frac{V_{b} \cdot \dot{P}_{B}-V_{p} \cdot \dot{P}_{A}}{\dot{P}_{A}-\dot{P}_{B}}
$$

$\dot{P_{A}}$ and $\dot{P_{B}}$ can be found from the initial gradient in Fig. 10 to be $0.37 \mathrm{MPa} / \mathrm{sec}$ and $0.19 \mathrm{MPa} / \mathrm{sec}$ respectively whilst the volume of the preform and bottle were measured to be $21.5 \mathrm{ml}$ and $675 \mathrm{ml}$ respectively. Substituting these values in to eq. 15 yields a value of $V_{D} \approx 670 \mathrm{ml}$. Since the dead volume is of the order 30 times greater than the original preform volume, it is obvious of the need to incorporate it into any calculations.

It was shown in Fig. 3, 5, 7 and 9 that the recorded temperature history of the cavity air during charging of the cold, rigid preforms and bottles indicate that the process is neither isothermal nor adiabatic. Some heat is lost to the machine parts and in the actual forming process, it can be expected that heat will be gained from the hot preform. However, during the blowing process, work is done from the inflating preform and without accurate knowledge of the volume evolution 
it cannot be estimated. It therefore is more sensible to calculate the flow rate from the pressure curves generated from charging of the rigid containers. Assuming isothermal conditions the mass flow rate in the initial choked phase can then be evaluated by eq. 11 , where $d p / d t$ is the initial slope of the pressure in the cavity and the volume $\mathrm{V}$ represents the volume downstream of the flow restrictor, composed of the dead volume and the preform/bottle volume.

Eq. 11 or eq. 16 both enable the flow rate to be estimated assuming choked conditions however it can be expected that during the ISBM forming process that the condition of $\mathrm{P}_{\text {bottle }}<0.528 \mathrm{P}_{\text {line }}$ will not always be met. Fig. 11 shows how the mass flow rate changes with the ratio between line pressure $\left(\mathrm{P}_{\text {line }}\right)$ and the pressure in the bottle $\left(\mathrm{P}_{\text {bottle }}\right)$.

By definition the flow in the choked region is constant up until a ratio of 0.528 , after which the flow decays in a non-linear fashion towards zero when the pressure in the bottle equals the line pressure. This graph can be described mathematically by eq. 16 and 17, where eq. 16 describes the flow in the choked region and the eq. 17 describes the flow in the un-choked region [13].

$$
\begin{gathered}
\dot{m}=\frac{C_{D} A_{T} P_{\text {line }}}{\sqrt{R T_{0}}} \gamma^{1 / 2}\left(\frac{2}{\gamma+1}\right)^{(\gamma+1) / 2(\gamma-1)} \\
\dot{m}=\frac{C_{D} A_{T} P_{0}}{\sqrt{R T_{0}}}\left(\frac{P_{\text {bottle }}}{P_{\text {line }}}\right)^{1 / \gamma}\left\{\frac{2 \gamma}{\gamma-1}\left[1-\left(\frac{P_{\text {bottle }}}{P_{\text {line }}}\right)^{(\gamma-1) / \gamma}\right]\right\}^{1 / 2}
\end{gathered}
$$

Formatted: equationY, Left

Where $C_{D}$ is the coefficient of discharge, $A_{T}$ is the cross section of the nozzle, $R$ is ideal gas constant, $\gamma$ is the specific heat ratio, $P_{\text {line }}$ is the absolute Air pressure in the supply line and $\mathrm{P}_{\text {bottle }}$ is the absolute air pressure in the bottle. 
The discharge coefficient and the cross section of the valve are not known; however, their product can be calculated. The implementation of these equations into AbaqusABAQUS will be discussed in the following section.

Using eq. 11 and 16 a value for the product of coefficient of discharge and the cross section of the nozzle $\left(C_{D} A_{T}\right)$ can be determined which can be substituted into eq. 17 to find the un-choked flow behaviour for each of the 8 combinations of flow index and supply pressure (Fig. 13).

\subsection{Rigid Pressurisation Simulation}

The pressure during blowing is a function of the supply line, flow control valve index, the volume of the preform and the "dead volume". The simulation package AbaqusABAQUS/Explicit used in this work conveniently permits input of the fluid mass flow rate as a function of pressure difference using the fluid exchange process. The volume is then calculated based on the deformation of the material caused by the accumulated pressure in each time step.

The objective of this simulation was to validate the mass flow and dead volume calculations by comparing the simulated internal pressure in the preform/bottle with the experimental internal pressure.

For the rigid pressurization simulation, an axisymmetric model representing the preform/bottle volume and the dead volume was created in AbaqusABAQUS, shown in Fig 14. The symmetric design of the preform along an axis can be utilized in building an axisymmetric model which reduces the simulation time. The entire model is encastred (held rigidly) so that the preform/bottle does not expand under pressure, which replicates the rigid pressurization tests. The shape or properties of the preform/bottle do not have any effect on the results as the model is completely 
rigid. A fluid exchange process was used for simulating the air flow seen in rigid pressurization test by supplying it with mass flow, as function of $\Delta \mathrm{P}$ (Fig. 15), where $\Delta \mathrm{P}$ is the difference between supply pressure and the preform internal pressure. AbaqusABAQUS interpolates linearly between the values specified. The calculated dead volume was incorporated into simulation such that the mass flow of air fills the dead volume/preform combination, thereby replicating the real rigid pressurization tests. It is also possible for the dead volume to be represented by a single node with an "added volume" equal to a value of $670 \mathrm{ml}$ as measured experimentally.

The fluid exchange process in the AbramsABAQUS/Explicit package requires the mass flow value to be supplied as a function of $\Delta \mathrm{P}$. The mass flow values as function of $\Delta \mathrm{P}$ are different for each experiment. Fig. 15 shows the mass flow values as function of $\Delta \mathrm{P}$ for the rigid pressurization experiment of a $675 \mathrm{ml}$ bottle at 7 bar pressure and $\mathrm{n}=1$.

\subsection{Rigid Pressurization Simulation Results}

From section 2.1, it can be recalled that flow characterization for the preform was carried out assuming isothermal conditions. For the rigid volume pressurization simulations, the cavity pressure output was compared to that obtained from the experimental analysis. The preform and bottle pressurization was compared for flow conditions 9 bar $n=1$, Fig. 16, and for flow conditions 9 bar $n=6$, Fig. 16 .

It can be seen in Fig. 16 and 17 that the simulation result matches very closely with the experiment. The predicted linear pressure gradient matched extremely well to that of the experimental gradient, with an $\mathrm{R}^{2}$ value of 0.999 for all rigid pressurization scenarios. This highlighted the fact that the flow calculation method and application to the simulation proved successful. The transition from choked flow to un-choked flow was also well predicted for the low flow condition i.e. the gradient 
reduction to constant pressure. This transition was predicted less successfully for the high flow rate. A large 'spike' in pressure was evident for the high flow rate condition after the linear gradient and before the pressure levelled out to the line pressure value. As was discussed earlier this speculated to be as a result of a shock wave. This prediction is not achievable using the fluid exchange options in AbaqusABAQUS and would require some form of computational fluid dynamics (CFD) in order to accurately calculate the air flow into the cavity at the higher flow rates. It is also not of great importance as this situation is as a result of the characterization method and is unlikely to occur in an actual stretch blow moulding process.

\subsection{Implications to ISBM Simulation}

As previously mentioned, the air mass flow rate is calculated directly from the linear pressure gradient for a given cavity/dead volume i.e. the air mass flow rate varies relative to the volume in order to return the correct pressure gradient. The dead volume therefore has no direct effect on the predicted cavity pressure results; adjustment of the air mass flow rate will account for this. Critically however, the acknowledged dead volume and correct air mass flow rate has a significant effect on the cavity pressure during the deformation of the preform i.e. non-rigid pressurization. To demonstrate this, a simulation has been setup of a previously performed free blow experiment $[15]$.

A full Design of Experiments was carried out at different preform temperatures while varying the air flow rate-and the pre blow timing.. The experiments were carried out on a semi-automatic lab scale machine produced by Vitalli and Son. This machine has a dead volume of $85 \mathrm{ml}$ which was calculated using the method described in sectionsection 3.0. The corresponding simulation was 
then also constructed with the calculated air mass flow rate for both rigid pressurization and freeblow scenarios.

\subsection{Free-blow Simulation Set-up}

The free-blow simulation was constructed in the same manner as the rigid pressurization simulation with the addition of a suitable sub-routine to represent the viscoelastic material behaviour of PET at temperature above Tg. The PET material used for the free-blow trail had a Tg of approximately $79^{\circ} \mathrm{C}$, an IV value of $0.81 \mathrm{dL} / \mathrm{g}$ and a density of $1.33 \mathrm{~g} / \mathrm{cm}^{3}$. The material model was developed by Shiyong Yan [16] and applied to the ABAQUS/Explicit ${ }^{\mathrm{TM}}$ FEA using a *VUMAT user sub-routine. The model was primarily based on the established Buckley model [17, 181; a constitutive model that utilised two parallel parts, the bond stretching part and the conformation part, Fig. 18. Each part of the constitutive model was represented by complex equations that required a large amount of data to perform accurate curve fitting procedures. The material data used for the curve fitting procedure, and as a result the material constants, were determined from extensive material testing using the QUB biaxial stretcher $[19,20]$ and strain history form the DIC analysis of the FSB trials. The biaxial testing was performed on $\underline{76 \times 76 \times 0.5 \mathrm{~mm} \text { samples of PET cut from extruded sheet, the same grade as the preform material. }}$ Yan then modified the model to take into account strain rate and deformation mode. During material testing, the temperature, strain rate and deformation mode were used as the parameters to attain the appropriate stress-strain curves. Table 2 displays the test parameters used to provide data for the characterisation procedure. 
The material model was built to take into consideration axisymmetric simulations (SAX1 shell elements) and full 3D simulations (S4R shell elements). Only SAX1 shell elements were used however for the preform for all the simulations in this work.

\subsection{Effect of Dead-volume}

The simulation of the rigid pressurization for the preform volume was initially performed using two volumes for the air mass flow calculation; the preform on its own, and the preform attached to the dead volume. The calculated air mass flow rate for the low flow rate setting was $1.4 \mathrm{~g} / \mathrm{s}$ for preform only and $6.7 \mathrm{~g} / \mathrm{s}$ for attached dead volume. For the high flow rate trial, the air mass flow rate was calculated to be $8.7 \mathrm{~g} / \mathrm{s}$ for preform only and $40.1 \mathrm{~g} / \mathrm{s}$ for attached dead volume. The air mass flow rate reduces as the volume is reduced in order to reproduce the same pressure gradient.

Fig. 1819 indicates that as expected the rigid pressurization for the two volume scenarios is the same; both scenarios would appear to be correct.

However, taking the cavity pressure results from two trials and comparing them to the predicted cavity pressure during free-blow analysis highlights the effect of neglecting the dead volume. These air mass flow rates with respective volumes were then applied to the free-blow simulation and the cavity pressure for each scenario was then compared to the experimental data, Fig. $19 \underline{20}$ and 2021.

The delay in the pressure rise for the low flow setting was due to a deliberate pre-blow timing delay. The effect of not accounting for the dead volume clearly had an effect on the cavity pressure results and to a further extent how the bottle deformed; each flow rate trial significantly underpredicted the cavity pressure. Examining each dead volume blowing scenario compared to the experimental results yields that the low flow set-up had an $\mathrm{R}^{2}$ value of 0.861 with the dead volume 
neglected and 0.985 when the dead volume was attached. The high flow set-up had an $\mathrm{R}^{2}$ value of 0.031 and 0.93 for the two dead volume set-ups respectively. It is important to remember that during the initial phase as the pressure rises, and contrary to the rigid pressurization trials, -the stretch rod deforms the preform therefore increasing the cavity volume. The change in cavity volume with respect to the initial volume is greater for the scenario where no dead volume is attached, and therefore has a greater effect on the resultant output cavity pressure.

Although the experimental and predicted pressure curves correlated successfully when the appropriate dead volume was attached, there was a certain amount of deviation as the free-blow bottle deformed. This was accounted for by the preform temperature profile used for the simulation and the material model used to capture the viscoelastic behaviour of PET. This can also be seen when the bottle shape evolution is examined.

\section{$\underline{5.3 \text { Free-blow Analysis }}$}

The free-blow experiments were performed using the lab-scale ISBM instrument located at Queen's University Belfast employing a speckle patterned preform and theheated using a silicone oil bath. The deformation was captured using high-speed stereoscopic CCD cameras-[R]. Digital image correlation analyses were then carried out to determine the strain levels on the deforming surface. The evolving bottle shape from the experiment was compared to that determined from the Abaqus simulation, Fig. 21, along with the bottle shape at critical time points on the pressure curveABAQUS simulation, along with the cavity pressure and true strain from the outside surface midpoint of the sidewall of the preform. The predicted results were then compared to the experimental values for low flow rate (Fig. 22) and high flow rate (Fig. 23) trials using the same preform temperature of $100^{\circ} \mathrm{C}$. 
The bottle shape comparison success deteriorates as the blowing process progresses from point $A$ to point E; contrary to the pressure curve which appeared to correlate with greater aceuracy. This highlights the fact that the mass flow rate and cavity pressure calculation is not governed by the eavity shape, but primarily the cavity volume.

The low flow rate trial exhibits excellent cavity pressure comparison with an $\mathrm{R}^{2}$ value of 0.95 . The evolving bottle comparison however indicated that the bottle profile differed between the simulation and the experiment; the simulation appeared to expand faster than the experiment. This was confirmed examining the true strain results with an $\mathrm{R}^{2}$ value of 0.92 for both the hoop and axial directions. The final strain values also indicate that the experimental bottle shape was bias in the axial direction i.e. slender bottle, while the predicted bottle shape was bias in the hoop direction i.e. fatter bottle. The high flow rate trial comparison shows a less accurately predicted cavity pressure than the low flow trial with an $\mathrm{R}^{2}$ value of 0.92 . Comparing the evolving bottles of the experiment and the simulation indicates that shape profile was predicted with high accuracy, emphasised by the surface strain results; comparison of the strain results had $\mathrm{R}^{2}$ values of 0.99 and 0.96 in the hoop and the axial directions respectively. The results highlight the fact that the mass flow rate and cavity pressure calculation is not governed by the cavity shape, but primarily the cavity volume.

The nature of the high flow rate preform expansion is primarily a form of biaxial deformation; although not purely equal biaxial, the deformation occurs simultaneously in the hoop and axial directions. The construction of the material model using the biaxial stretching machine utilised biaxial deformation therefore resulting in an accurately predicted high flow rate free-blow simulation. Contrary to this, the low flow rate preform expansion takes the form of a sequential type i.e. a linear axial stretch followed by a biaxial inflation. The material characterisation 
technique using the biaxial stretching machine was not able to replicate the sequential deformation type for every foreseeable stretch scenario; indeed, only constant width and pure biaxial deformation were captured. The amount of initial linear stretch, and therefore the onset of orientation and eventual strain hardening [19-29], significantly affects the inflation of the preform.

\subsection{Conclusions}

An experimental methodology for determining the flow rate on an industrial injection stretch blow moulding machine has been described. The ideal gas law with the assumption of isothermal conditions for the air has been used to calculate the flow rate. Whilst the experimental measurement of temperature indicates that this assumption is not ideal, it has been demonstrated that it is adequate for giving a realistic representation of the flow rate for an injection stretch blow moulding process.

The experiments have also highlighted a methodology for determining the "dead volume" on a blow moulding machine and the corresponding numerical simulations highlight the importance of representing this volume in order to obtain accurate blow moulding simulations. The data generated has been used to setup a coupled fluid structure interaction problem in the commercial finite element package Abaqus $\underline{A B A Q U S}$ assuming an ideal gas law for an incompressible compressible fluid under isothermal conditions. The simulations are able to replicate the rigid charging experiments accurately except in the case where shock waves occur due to the high flow. The methodology developed has been applied to determine the flow characteristics of an additional blow moulding machine which has the capability of performing free-blow experiments whilst monitored via high speed camera. The correlations between the model and the experimental data 
for both evolving preform shape and the pressure vs time inside the preform validate the mass flow measurements. 
Table 1: Summary of experiments used in charging fixed volumes

\begin{tabular}{|l|c|c|c|}
\cline { 2 - 4 } \multicolumn{2}{c|}{} & $\begin{array}{c}\text { Flow index } \\
\text { (preform) }\end{array}$ & $\begin{array}{c}\text { Flow index } \\
\text { (bottle) }\end{array}$ \\
\hline $\begin{array}{l}\text { Gauge pressure } \\
\text { (MPa) }\end{array}$ & 0.7 & $1 ; 2 ; 4 ; 6$ & $1 ; 2 ; 4 ; 6$ \\
\cline { 2 - 4 } & 0.9 & $1 ; 2 ; 4 ; 6$ & $1 ; 2 ; 4 ; 6$ \\
\hline
\end{tabular}

Formatted: Font: $16 \mathrm{pt}$

Formatted: Centered

Table 2: Summary of testing parameters for material characterisation

\begin{tabular}{|c|c|c|}
\hline$\underline{\text { Temperature }\left({ }^{\circ} \mathbf{C}\right)}$ & $\underline{\text { Strain Rate }(/ \mathbf{s})}$ & Deformation Mode \\
\hline$\underline{90}$ & $\underline{1}$ & $\underline{\text { Biaxial }}$ \\
\hline$\underline{95}$ & $\underline{2}$ & $\underline{\text { Constant width }}$ \\
\hline$\underline{100}$ & $\underline{4}$ & \\
\hline$\underline{105}$ & $\underline{8}$ \\
\hline$\underline{110}$ & $\underline{16}$ \\
\hline
\end{tabular}




\section{References}

1. L. Chevalier, Y. Marco, Mech. Mater., 39, 6, 596, (2007)

2. Chevalier, L.; Luo, Y.M.; Monteiro, E.; Menary, G.H, Mech Mater, 52, (2012),

3. B. Cosson, L. Chevalier, J. Yvonnet, Int J Mater Form. 1, 707, (2008)

4. Billon, N., Picard M., Gorlier E., Int J Mater Form ,DOI: 10.1007/s12289-013-1131-1

5. Hopmann, C, Michaeli, W., Rasche, $\mathrm{S}, 14^{\text {th }}$ International Esaform conference on Material Forming, Belfast, N. Ireland, (2011)

6. F. Erichiqui., A. Bendana, IJSPM, 27, 3, (2007)

7. M. Bordival, F. M. Schmidt, Y. Le Maoult V. Velay, Polym Eng. Sci., 49, 4, 783 (2009).

8. Y. M. Salomeia, G. H. Menary, C. G. Armstrong, Adv Poly Tech. 32, 436, (2013)

9. F. M. Schmidt, J.F. Agassant, M. Bellet, Polym Eng. Sci., 38, 9, 1399, (1998)

10. H. Mir, F. Thibault, R. Diraddo, Polym Int, 2011, 2, 173, (2011) 
11. G.H. Menary, C.W. Tan, C.G. Armstrong, Y. Salomeia, M. Picard, N. Billon, E. HarkinJones, Polym Eng. Sci., 50, 5, 1047, (2010)

12. Y. M. Salomeia, G. H. Menary, C. G. Armstrong, Adv Poly Tech. 32, 771, (2013)

13. J. B. Heywood, "Internal Combustion Engine Fundamentals", McGraw-Hill, New York (1988).

14. M. D. Bughardt and J. A. Harbach, "Engineering Thermodynamics”, Cornell Maritime Press, Centreville, Maryland, 4 ed., (1993).

15. J. Nixon, S. Yan, G. Menary, Key Eng Mater, 554-557, 1729, (2013)

16. S. Yan, "Modelling the Constitutive Behaviour of Poly(ethylene terephthalate) for the Stretch Blow Moulding Process” PhD thesis, Queen's University Belfast, (2013)

17. C. P. Buckley, D. P. Jones, Polymer, 36, 3301, (1995)

18. C.P. Buckley, D. P. Jones, Polymer, 17, 2403, (1996)

19. G. H. Menary, C. W. Tan, C. G. Armstrong, Key Eng Mat, 1117, 504, (2012)

20. G. H. Menary, C. W. Tan, E. M. Harkin-Jones, C. G. Armstrong, P. J. Martin, Polym Eng $\underline{\text { Sci, 52, 671, (2011) }}$

21. L. Chevalier, Y. Marco, Mech of Mat, 39, 596, (2007)

22. Y. Marco, L. Chevalier, M. Chaouche, Polymer, 43, 6569, (2002)

23. S. Ahzi, A. Makradi, R. V. Gregory, D. D. Edie, Mech of Mat, 35, 1139, (2003)

24. E. Gorlier, J. M. Haudin, N. Billon, Polymer, 42, 9514, (2001)

25. C.I. Martins, M. Cakmak, Polymer, 48, 2109, (2007)

26. E. Deloye, J-M. Haudin, N. Billon, Int J Mater Form, 1, 715, (2008)

27. N. Billon, M. Picard, E. Golier, Int J Mater Form, 7, 369, (2014) 
28. A. Mahendrasingam, C. Martin, W. Fuller, D. J. Blundell, R. J. Oldman, J. L. Harvie, D.

H. Mackerron, C. Riekel, P. Engstrom, Polymer, 40, 5553, (1999)

29. A. Mahendrasingam, D. J. Blundell, C. Martin, W. Fuller, D. H. MacKerron, J. L. Harvie,

R. J. Oldman, C. Riekel, Polymer, 41, 7803, (2000)

15.
Formatted: Normal, No bullets or numbering, Adjust space between Latin and Asian text, Adjust space between Asian text and numbers 


\section{Figure Captions}

Fig 1: Schematic diagram of the ISBM pneumatic system

Fig 2: Experimental measurement of pressure for preform charging with $0.7 \mathrm{MPa}$ supply pressure

Fig 3: Experimental measurement of temperature for preform charging with $0.7 \mathrm{MPa}$ supply pressure

Fig 4: Experimental measurement of pressure for bottle charging with $0.7 \mathrm{MPa}$ supply pressure

Fig 5: Experimental measurement of temperature for bottle charging with $0.7 \mathrm{MPa}$ supply pressure Fig 6: Experimental measurement of pressure for preform charging with $0.9 \mathrm{MPa}$ supply pressure

Fig 7: Experimental measurement of temperature for preform charging with $0.9 \mathrm{MPa}$ supply pressure

Fig 8: Experimental measurement of pressure for bottle charging with $0.9 \mathrm{MPa}$ supply pressure

Fig 9: Experimental measurement of temperature for bottle charging with $0.9 \mathrm{MPa}$ supply pressure

Fig 10: Linear pressure gradient for preform and bottle pressurisation under flow conditions 7 bar and $n=1$

Fig 11: Schematic of choked and un-choked flow

Fig 12: Maximum (choked) mass flow rate as a function of line pressure and flow index

Fig 13: Calculated un-choked mass flow rate of rigid pressurization tests as a function of pressure ratio

Fig 14: Screen shot of 2D axisymmetric model used for the simulation of the rigid pressurisation test

Fig 15: Mass flow as function of $\Delta \mathrm{P}$ for the rigid pressurisation test of bottle at 7 bar and $n=1$

Fig 16: Comparison of predicted and experimental pressure for rigid pressurisation using flow conditions at 9 bar and $n=1$; rigid preform and bottle 
Fig 17: Comparison of predicted and experimental pressure for rigid pressurisation using flow conditions at 9 bar and $n=6$; rigid preform and bottle

Fig 18Fig 18: Constitutive characteristic of the Buckley model

Fig 19: Rigid pressurisation of preform with and without dead volume attached; low flow and high flow rate

Fig 19: Experiential and predicted cavity pressure comparison for each dead volume scenario; low flow rate

Fig 20: Experiential and predicted cavity pressure comparison for each dead volume scenario; low flow rate

Fig 21: Experiential and predicted cavity pressure comparison for each dead volume scenario; high flow rate

Fig 2122: Evolving bottle shape for low flow rate trial with critical time points from pressure curve and strain mapping; experiment and simulation

Fig 23: Evolving bottle shape for high flow rate trial with critical time points from pressure curve and strain mapping; experiment and simulation 